\title{
BMJ Open Training general practitioners in melanoma diagnosis: a scoping review of the literature
}

\author{
Evelyne Harkemanne (D) ,1,2 Marie Baeck (D) ,1,2 Isabelle Tromme ${ }^{1,3}$
}

To cite: Harkemanne E, Baeck M, Tromme I. Training general practitioners in melanoma diagnosis: a scoping review of the literature. BMJ Open 2021;11:e043926. doi:10.1136/ bmjopen-2020-043926

- Prepublication history and additional materials for this paper is available online. To view these files, please visit the journal online (http://dx.doi. org/10.1136/bmjopen-2020043926).

Received 18 August 2020 Revised 03 March 2021 Accepted 09 March 2021

Check for updates

(C) Author(s) (or their employer(s)) 2021. Re-use permitted under CC BY-NC. No commercial re-use. See rights and permissions. Published by BMJ.

${ }^{1}$ Service de dermatologie, Cliniques universitaires SaintLuc, Bruxelles, Belgique ${ }^{2}$ Pôle de pneumologie et dermatologie, Institut de Recherche Expérimentale et Clinique, UCLouvain, Bruxelles, Belgique

${ }^{3}$ Clinique du mélanome, Institut Roi Albert II, Cliniques universitaires Saint-Luc, Bruxelles, Belgique

Correspondence to Dr Evelyne Harkemanne; evelyne.harkemanne@ uclouvain.be

\section{ABSTRACT}

Background General practitioners (GPs) play a key role in early melanoma detection. To help GPs deal with suspicious skin lesions, melanoma diagnostic training programmes have been developed. However, it is unclear whether these programmes guarantee the acquisition of skills that will be applied by GPs in their daily clinical practice and maintained over time.

Objectives This scoping review aimed to examine and compare educational programmes designed to train GPs in melanoma diagnosis using clinical (naked eye) examination alone or dermoscopy \pm clinical examination, and sought to inform on the long-term sustainability of the GPs' acquired skills.

Eligibility criteria Studies eligible for inclusion evaluated educational programmes for teaching diagnosis of melanoma to GPs. MEDLINE, EMBASE and Cochrane databases were searched for relevant articles from 1995 to May 2020.

Results Forty-five relevant articles were found assessing 31 educational programmes. Most programmes that improved the diagnostic accuracy and long-term performances of the GPs, that is, increase in confidence, decrease in dermatologist referral for benign skin lesions and improvement in the benign/malignant ratio of excised skin lesions, trained the GPs in clinical diagnosis, followed by dermoscopy. To maintain long-term performances, these programmes provided refresher training material. Conclusion This review shows that studies generally report positive outcomes from the training of GPs in melanoma diagnosis. However, refresher training material seemed necessary to maintain the acquired skills. The optimal form and ideal frequency for these updates have yet to be defined.

\section{INTRODUCTION}

Early melanoma detection is essential to reduce the morbidity and mortality of patients with melanoma. ${ }^{1}$ Given the increased incidence of this aggressive skin cancer, primary care physicians (PCPs) play a key role in early melanoma diagnosis. ${ }^{2-4}$ PCPs include a number of healthcare professionals who provide first and continuing medical care to a patient. In this review, we focus on general practitioners (GPs) who take care of patients in community settings and are, in most

\section{Strengths and limitations of this study}

- Systematic review was conducted following the guidelines of the Preferred Reporting Items for Systematic reviews and Meta-Analyses extension for Scoping Reviews checklist.

- It thoroughly evaluates educational programmes on melanoma diagnosis for general practitioners.

- Specifically, the review examines the long-term effect of educational programmes and the value of providing regular refresher training sessions after the training.

- This review led inevitably to some publication bias as only English-language peer-reviewed articles were included.

countries, the first point of contact for any patient with a health issue.

To improve the diagnostic accuracy of melanoma by GPs, specific educational training programmes have been developed. At first, training courses focused on melanoma diagnosis by clinical (naked eye) examination alone. A systematic review, ${ }^{5}$ published in 2011, reported on 20 studies that evaluated 13 educational interventions in clinical melanoma diagnosis for PCPs. All the evaluated interventions improved diagnostic accuracy and melanoma management. Later, educational programmes that included dermoscopy training were created and then evaluated for primary care. To date, dermoscopy has been the most widely used noninvasive in vivo technique in clinical practice to assess skin tumours. ${ }^{6}$ It involves the use of a handheld device that allows the observation of skin structures invisible to the naked eye. However, the sensitivity and specificity of the technique are operator-dependent (trained vs untrained physicians). ${ }^{7}$ Ninety-two percent sensitivity and $95 \%$ specificity can be achieved for melanoma diagnosis by a trained dermatologist combining visual inspection and in vivo dermoscopy. ${ }^{8}$ In primary care, dermoscopy has also been shown to be an effective 
tool for the triage of suspicious pigmented skin lesions when performed by properly trained PCPs. ${ }^{9}{ }^{10}$ Yet, the minimum training required to reach competence is still unknown. ${ }^{11}$

Previously published reviews ${ }^{5}$ 11-14 on training programmes in melanoma diagnosis for GPs focused on the content, teaching method, outcome measures and study-by-study efficacy of the evaluated educational interventions. However, they did not assess whether the GPs' acquired skills were measured in the short or long term. Yet, given the increasing burden of melanoma on general practice, it is crucial to know whether these programmes are capable of teaching GPs easily applicable and sustainable skills in melanoma diagnosis and management. This scoping review aimed to explore educational programmes training GPs in melanoma diagnosis using clinical (naked eye) examination alone and diagnosis using dermoscopy \pm clinical examination. Educational programmes were examined regarding training content, teaching method, training duration, availability of refresher training material and outcome measures. This review also specifically sought to inform on the long-term sustainability of the skills acquired during these training programmes.

\section{MATERIAL AND METHODS}

To carry out this literature review, a scoping review seemed the most appropriate research method. Indeed, the studies we identified, which provided evidence on the efficacy of educational programmes in melanoma diagnosis for GPs, showed a wide range of study designs and heterogeneous outcome measures. This observation made it impossible to formally assess the quality of these studies and to perform a meta-analysis, leading to a narrative synthesis of our research results. To conduct this scoping review, the framework developed by Arksey and O'Malley, ${ }^{15}$ subsequently refined by Levac et al, ${ }^{16}$ and the guidelines of the PRISMA-ScR ${ }^{17}$ (Preferred Reporting Items for Systematic reviews and Meta-Analyses extension for Scoping Reviews) checklist were followed.

\section{Eligibility criteria}

Studies eligible for inclusion in this review (box 1) evaluated educational programmes teaching either clinical diagnosis of melanoma or diagnosis using dermoscopy \pmclinical examination and designed primarily for PCPs including GPs. The population of interest included qualified GPs and GP trainees. Specialists and GPs working in hospital settings and/or specialised clinics were excluded. Studies that included training programmes for PCPs other than GPs were not eligible. Studies where no participant training in melanoma diagnosis was proposed and studies evaluating exclusively non-melanoma skin cancer detection were also excluded. Studies evaluating teledermoscopy and computer-aided diagnosis of melanoma were not assessed as they do not require specific education in melanoma recognition by the participants. Only studies assessing the type of educational programme
Box 1 Inclusion and exclusion criteria for article selection

Inclusion criteria:
Articles
Articles written in English.
Study articles and descriptive articles of educational programmes.
Population
Qualified GPs and GP trainees working in community settings.
Intervention
Studies evaluating educational programmes in clinical (naked eye)
diagnosis and/or diagnosis of melanoma using dermoscopy.
Outcome(s)
Studies assessing the type of educational programme and its short-
term and/or long-term efficacy on the skills acquired by the GPs.
Exclusion criteria:
Articles
Articles not subject to peer review and written in languages other
than English.
Population
Studies involving specialists, medical students, non-GPs, GPs work-
ing in hospital settings and/or specialised skin cancer clinics.
Intervention
Abbreviations: GPs, general practitioners.
Teledermoscopy studies.
Outcome(s)

and its short-term and/or long-term efficacy on the skills acquired by the GPs were included. Finally, only peerreviewed and English-language articles were included.

\section{Data sources and study selection}

MEDLINE, EMBASE and Cochrane databases were searched for relevant articles published from 1995 to May 2020. Studies were selected for inclusion independently by three authors (EH, MB and IT), with IT providing the final decision in the event of disagreement. The studies were not assessed for bias, as the risk of bias assessment was reported as not applicable to scoping reviews in the 2018 PRISMA-ScR guidelines. ${ }^{17}$

To extensively cover the literature on the subject, four categories of terms were identified: (1) GPs, family doctor, general medicine, family practice and PCPs; (2) education and continuing medical education; (3) melanoma, malignant melanoma, cutaneous melanoma and skin neoplasms; and (4) diagnosis and early detection of cancer. In MEDLINE, the following Medical Subject Headings were used: general practitioners OR family practice OR primary care physicians OR general practice AND melanoma AND diagnosis. No limits were defined. In EMBASE, Emtree terms were exploded: general practitioner, family doctor, primary care, family physician, primary care physician, melanoma, diagnosis and education. In the Cochrane database, the following terms were searched: melanoma AND diagnosis AND general practitioners OR family medicine AND dermoscopy (see online supplemental table 1 for search 
Table 1 Definition of study categories

\begin{tabular}{|c|c|c|}
\hline Criteria & Categories & Definition \\
\hline \multirow[t]{6}{*}{ Training content } & Epidemiology & $\begin{array}{l}\text { Background information on rates of melanoma cancer, risk factors, localisation } \\
\text { and evolution of melanomas }\end{array}$ \\
\hline & Clinical diagnosis & Naked eye melanoma recognition \\
\hline & Clinical algorithm & Use of a pre-existing algorithm as a learning tool to aid for clinical diagnosis \\
\hline & Dermoscopic diagnosis & Recognition of melanoma using dermoscopy \\
\hline & Dermoscopic algorithm & Use of an algorithm as a learning tool to aid for dermoscopic diagnosis \\
\hline & Management & $\begin{array}{l}\text { Determination of a plan of action for a skin lesion, that is, reassurance, follow- } \\
\text { up or lesion excision }\end{array}$ \\
\hline \multirow[t]{4}{*}{ Teaching method } & Live & Presentation by a speaker to a group of participants \\
\hline & Scientific literature & Use of educational books, posters, letters, CD-ROMs or videos \\
\hline & E-learning & Interactive online tutorials including audio and visual information \\
\hline & Self-assessment & Learning by the participant himself using educational material \\
\hline $\begin{array}{l}\text { Refresher training } \\
\text { material }\end{array}$ & $\begin{array}{l}\text { Teledermatology } \\
\text { feedback }\end{array}$ & $\begin{array}{l}\text { Feedback from a dermatologist on the image and clinical history of a suspicious } \\
\text { lesion at a distance, using remote internet-based technologies }\end{array}$ \\
\hline \multirow[t]{5}{*}{ Outcome measures } & Competences & $\begin{array}{l}\text { Acquired skills, which are evaluated in a training setting on clinical and/or } \\
\text { dermoscopic photographs of skin lesions }\end{array}$ \\
\hline & Diagnostic accuracy & Ability of the participants to discriminate between melanoma and benign lesions \\
\hline & Knowledge & Report of conceptual understanding \\
\hline & $\begin{array}{l}\text { Appropriate } \\
\text { management }\end{array}$ & Determination of the right plan of action for a skin lesion \\
\hline & Performances & $\begin{array}{l}\text { Changes in real-life practice measured in a clinical setting, that is, changes in } \\
\text { the benign/malignant ratio of excised lesions, the number of total-body skin } \\
\text { examinations performed, confidence of the general practitioners, changes in } \\
\text { referral rates to a dermatologist and decrease in the incidence of advanced } \\
\text { melanomas }\end{array}$ \\
\hline \multirow[t]{2}{*}{ Evaluation } & Short-term & Measurement of outcomes immediately or up to 3 months after the training \\
\hline & Long-term & Measurement of outcomes at $\geq 6$ months after the training \\
\hline
\end{tabular}

strategies). In addition, the reference lists of included studies were screened as a source of further relevant articles.

\section{Data extraction}

Two authors (EH and $\mathrm{MB}$ ) reviewed all included articles and independently collected data. Extracted data included authors, year of publication, origin of the article, study design, number of participating GPs, type of educational programme, type of outcome measures and short-term and/or long-term evaluation of these outcomes. The type of educational programme included training content, teaching method, training duration and refresher training material (if provided). To facilitate comparison with data found in previous reviews, all these data were reported into categories adapted from those presented by Fee et $_{\text {al. }}{ }^{14}$

Table 1 gives the definition of the different categories. The training content was subdivided into six components: epidemiology, clinical diagnosis, clinical algorithm, dermoscopic diagnosis, dermoscopic algorithm and management. The teaching method was considered as live, in the form of scientific literature, e-learning or self-assessment. The refresher training material specified the material available for participants to refresh their skills after the training. The outcome measures were expressed either in terms of competence or in terms of performance, according to the assessment approach of continuing medical education programmes proposed by Moore. ${ }^{18}$ Finally, since the limits between short-term and long-term evaluation of a medical educational programme are not standardised, arbitrary limits have been chosen based on the observations made during this literature review.

\section{Patient and public involvement}

No patient and public involvement was required for this review.

\section{RESULTS}

In total, 325 articles were identified from the electronic database searches, as shown in the PRISMA flowchart (figure 1). ${ }^{19}$ At the end of the study selection process, 45 relevant articles, which assessed 31 educational interventions, were included in the review analysis.

\section{Study designs}

Thirty-six interventional studies with a range of study designs were found: 11 randomised controlled trials 


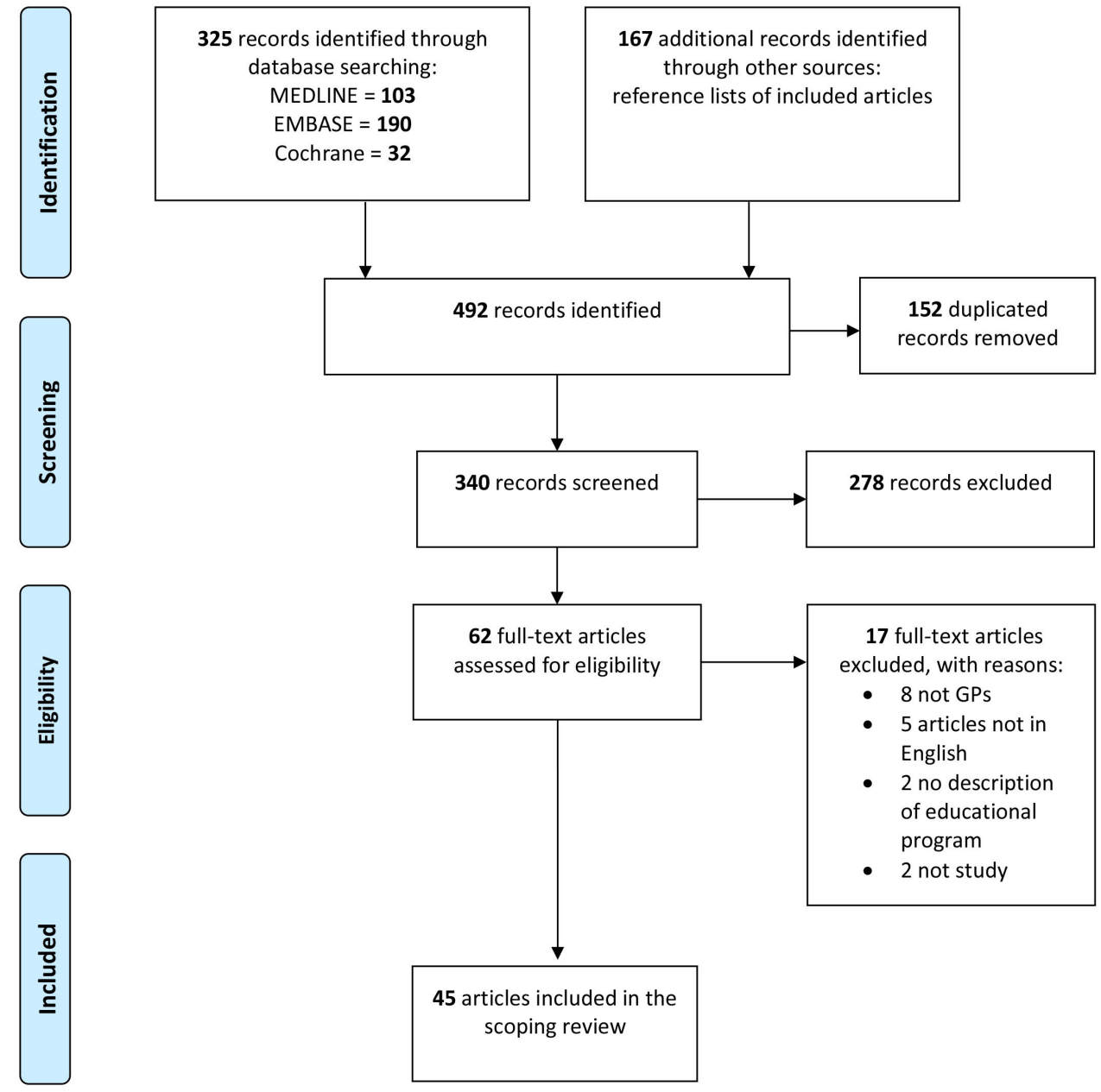

Figure 1 Preferred Reporting Items for Systematic reviews and Meta-Analyses flowchart of the study selection process. ${ }^{17}$ GP, general practitioner.

(RCTs), ${ }^{9} 10 \quad 20-2919$ diagnostic accuracy studies, ${ }^{30-48} 3$ cohort studies ${ }^{49-51}$ and 3 case-control studies. ${ }^{52-54}$ Five of the 31 training programmes were assessed twice. ${ }^{25} 26283249$

Four systematic reviews were identified: one on the training of PCPs in clinical melanoma diagnosis, ${ }^{5}$ two on the training of PCPs in dermoscopy for melanoma diagnosis ${ }^{12} 13$ and one on the use of dermoscopy in primary care. ${ }^{11}$ A scoping review on the training of PCPs in dermoscopy ${ }^{14}$ was also included. The final three articles were descriptive articles of the educational programmes and study protocols. ${ }^{55-57}$

\section{Educational programmes}

The educational programmes in melanoma diagnosis for GPs varied in terms of content, teaching method and outcome measures. The characteristics of these training programmes are summarised in table 2.

\section{Training content}

Of the 31 educational programmes, 15 involved the training of GPs in clinical diagnosis, 5 involved dermoscopic diagnosis alone and 11 involved the training of GPs in both of these melanoma diagnostic methods. Twelve $(80 \%)$ of the clinical diagnostic training programmes also involved learning of epidemiology and
$11(73 \%)$ involved learning of management guidelines for suspicious lesions. Only seven $(47 \%)$ programmes teaching clinical diagnosis used an algorithm to teach melanoma recognition, with the $\mathrm{ABCD}(\mathrm{E})$ rule $^{58}$ (Asymmetry, uneven Borders, uneven Colours, Diameter $>6 \mathrm{~mm}$ and Evolution) being most commonly taught. Of the dermoscopic training programmes, $12(80 \%)$ included learning of at least one dermoscopic algorithm (Menzies method, ${ }^{24} 353740$ three-point checklist, ${ }^{9} 4041$ seven-point checklist, ${ }^{10} 35$ triage amalgamated dermoscopic algorithm (TADA),${ }^{44} 47$ the ABCD rule, ${ }^{35}{ }^{38}$ BLINCK $^{40}$ and pattern analysis $^{35}{ }^{54}$ ). The Menzies method, ${ }^{59}$ the ABCD rule, ${ }^{60}$ pattern analysis and seven-point checklist ${ }^{61}$ were designed originally for trained physicians and were later tested as effective when used by non-experts. ${ }^{62}$ Other algorithms, such as the three-point checklist ${ }^{63}$ and the TADA, ${ }^{44}$ were initially created for use by PCPs. In addition, two educational programmes included training on other diagnostic tools, such as sequential digital dermoscopy imaging ${ }^{37}$ and polaroid instant camera photography. ${ }^{26}$

Teaching method, training duration and refresher training material Live training courses and the use of educational books, posters or videos (literature) were the two preferred 


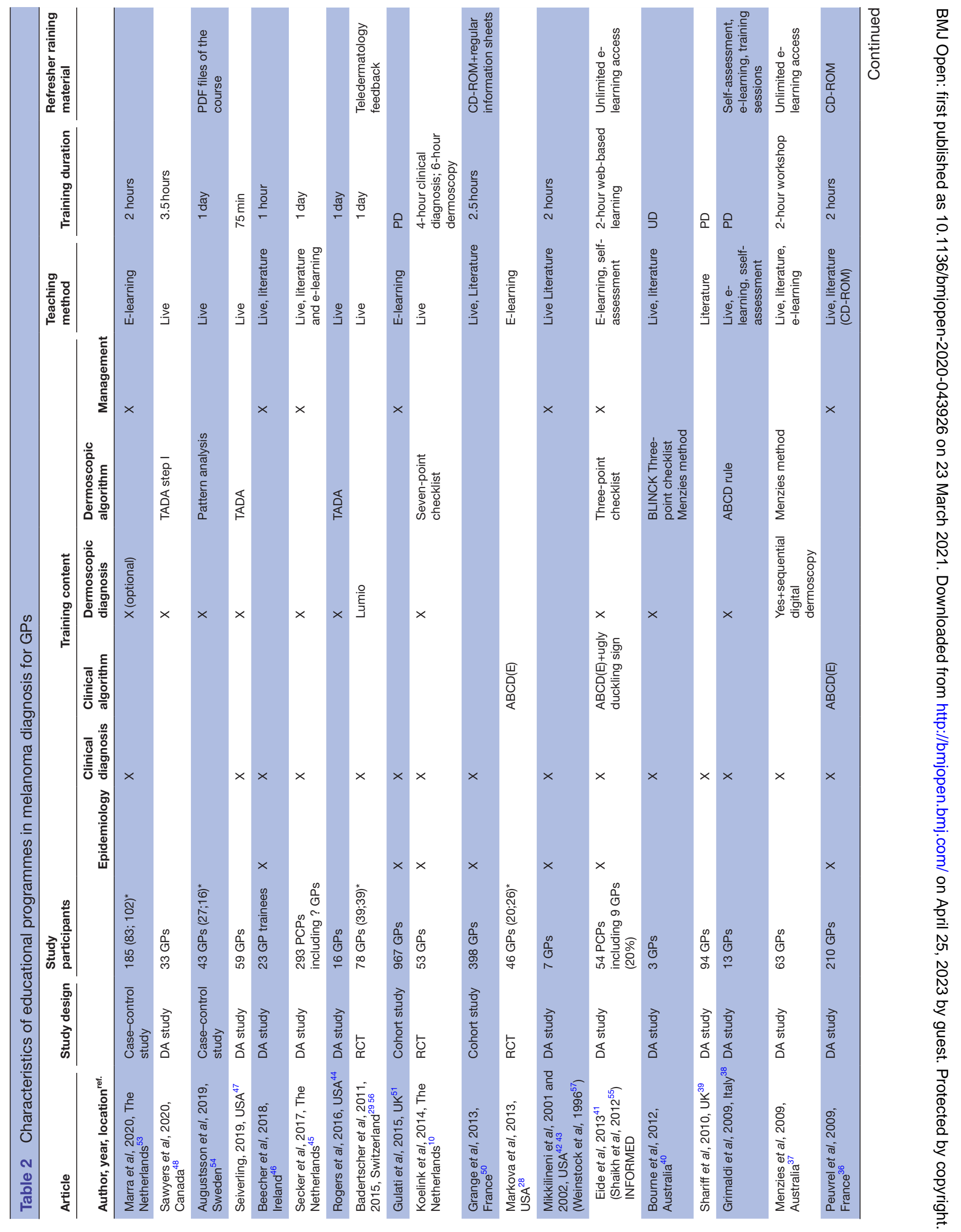




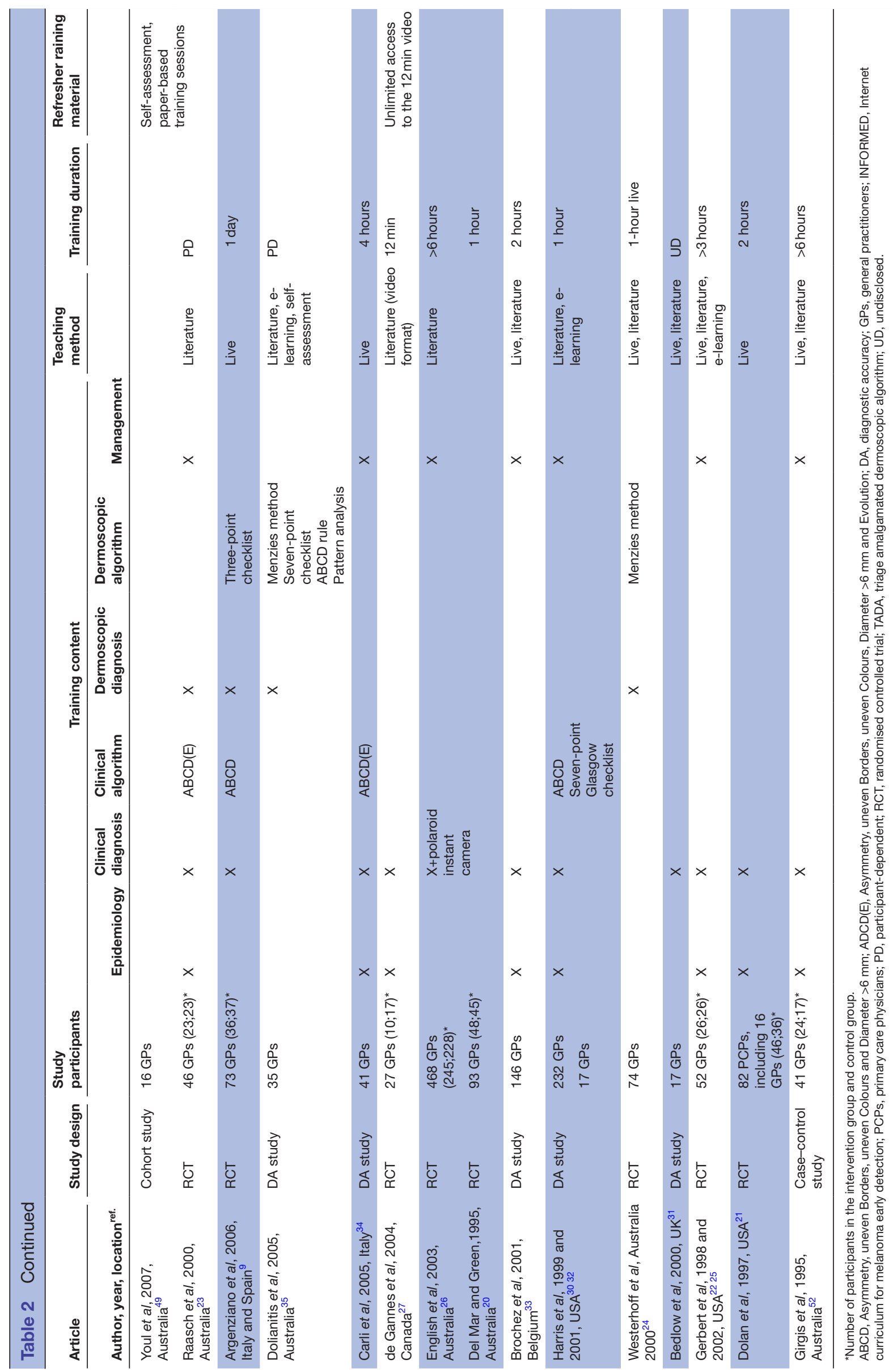


teaching methods of clinical diagnostic training programmes. Five training programmes also used an e-learning approach. ${ }^{2528305153}$ The most common teaching method used in dermoscopic training programmes was live training. This approach was combined with literature and/or e-learning in six programmes. Three programmes also used self-assessment. Overall, the teaching method did not appear to have influenced the programme outcomes. Duration of training varied from 75 min to 1 day, was not specified in two studies ${ }^{3140}$ and was participant-dependent in six studies using selfassessment methods. Six dermoscopic diagnostic training programs $^{29} 3738414954$ and three programmes in clinical diagnosis ${ }^{27} 3650$ provided regular refresher training material such as unlimited e-learning access or self-assessment training sessions.

\section{Training outcomes}

Table 3 summarises the outcome measures of the studies. In the selected studies, the GPs' competences were generally measured in the short term and their performances measured in the long term after the training.

Eight clinical diagnostic training programmes and seven dermoscopic training programmes only assessed the short-term efficacy of their programme (table 3A). For these studies, the competences most often evaluated were diagnostic accuracy and appropriate management measured in a training setting. The most evaluated shortterm performance, measured in a clinical setting, was the GPs' confidence in diagnosing melanoma. With the exception of two studies, all showed a positive impact of their intervention. ${ }^{21}{ }^{23}$ Four clinical diagnostic training programmes and three dermoscopic training programmes (one teaching dermoscopy alone ${ }^{54}$ ) only assessed longterm performances (table 3B). The most evaluated longterm performances, measured in daily clinical practice, were the GPs' diagnostic accuracy and the benign/malignant ratio of excised lesions. Three studies ${ }^{93649}$ reported improvement in the GPs' performances in melanoma diagnosis. The other studies reported no improvement.

Finally, three clinical diagnostic and seven dermoscopic training programmes assessed the short-term and long-term outcome of their training (table 3C). Except for one, ${ }^{23}$ all these training programmes demonstrated improvement in the GPs' competences, measured in a training setting in the short term. In the long term, eight training programs ${ }^{10} 37384149505354$ reported significant improvement in the GPs' performances for the diagnosis of melanoma and benign skin lesions. This led to either a decrease in the referral rates to dermatologists ${ }^{37} 4153$ or a decrease in the ratio of benign/malignant excised skin lesions. ${ }^{3749}$ Among the major studies, Koelink et $a l^{10}$ found that their dermoscopic training programme improved the GPs' long-term performances with up to 1.25 times greater diagnostic accuracy for skin lesions including melanomas. In a French department, Grange $e t a \tilde{p}^{0}$ observed an impressive reduction in the incidence of advanced melanomas (Breslow thickness $\geq 3 \mathrm{~mm}$ ) during the 3-year period after their GP training campaign in clinical melanoma diagnosis. A very recent study by Marra $e t a \tilde{p}^{\tilde{3}}$ assessing 1662 referrals reported better quality of referrals by GPs trained in melanoma diagnosis than by untrained GPs, potentially leading to less unnecessary referrals. However, two educational programs $^{28} 29$ were unable to maintain the GPs' acquired performances in the long term.

\section{DISCUSSION}

This scoping review aimed to explore educational programmes training GPs in melanoma diagnosis using clinical (naked eye) examination alone and diagnosis using dermoscopy \pm clinical examination. Educational programmes were examined regarding training content, teaching method, training duration, availability of refresher training material and outcome measures. This review also specifically sought to inform on the long-term sustainability of the skills acquired during these training programmes.

\section{Types of educational programmes with positive long-term outcomes}

Most reported educational programmes that improved long-term diagnostic accuracy and changed GPs' melanoma practice patterns trained their participating GPs in dermoscopy combined with clinical diagnosis. This teaching method is supported by a recent Cochrane review $^{8}$ in which dermoscopy alone was found to be less accurate than clinical examination followed by dermoscopy for the diagnosis of melanoma. The Cochrane review results also suggested that dermoscopic algorithms were the most useful method to train non-experts in dermoscopy. In our review, we found that five of the programmes with long-term positive impact used dermoscopic algorithms to teach melanoma diagnosis. ${ }^{10} 37384154$

Unfortunately, the substantial number of training hours necessary to become competent in dermoscopy is the main reported factor limiting its use in general practice. ${ }^{645}$ At this time, there is no evidence on the optimal length of training, even though it has been demonstrated that diagnostic accuracy of dermoscopy depends on the degree of training of the practitioner. ${ }^{66}$ One study suggested that 1 day of live training in dermoscopy was sufficient to build the confidence of GPs with special interest in melanoma diagnosis. ${ }^{67}$ We found two RCTs that demonstrated sustained improvement in GPs' diagnostic accuracy, both of which proposed live training in dermoscopy over 1 day or 10 hours. ${ }^{910}$ Because the duration of training in dermoscopy is a limiting factor for most GPs, it is important to keep in mind that training in clinical melanoma diagnosis has also been shown to improve the GPs' performances while requiring less training time (in this review, a mean duration of 2.5 hours was observed for clinical diagnostic training programmes). ${ }^{36} 50$

However, we found that educational programmes teaching dermoscopy have been more likely to assure positive long-term outcomes than programmes teaching clinical examination alone. One of the reasons could be that the latter used measures of performance such as GPs' 


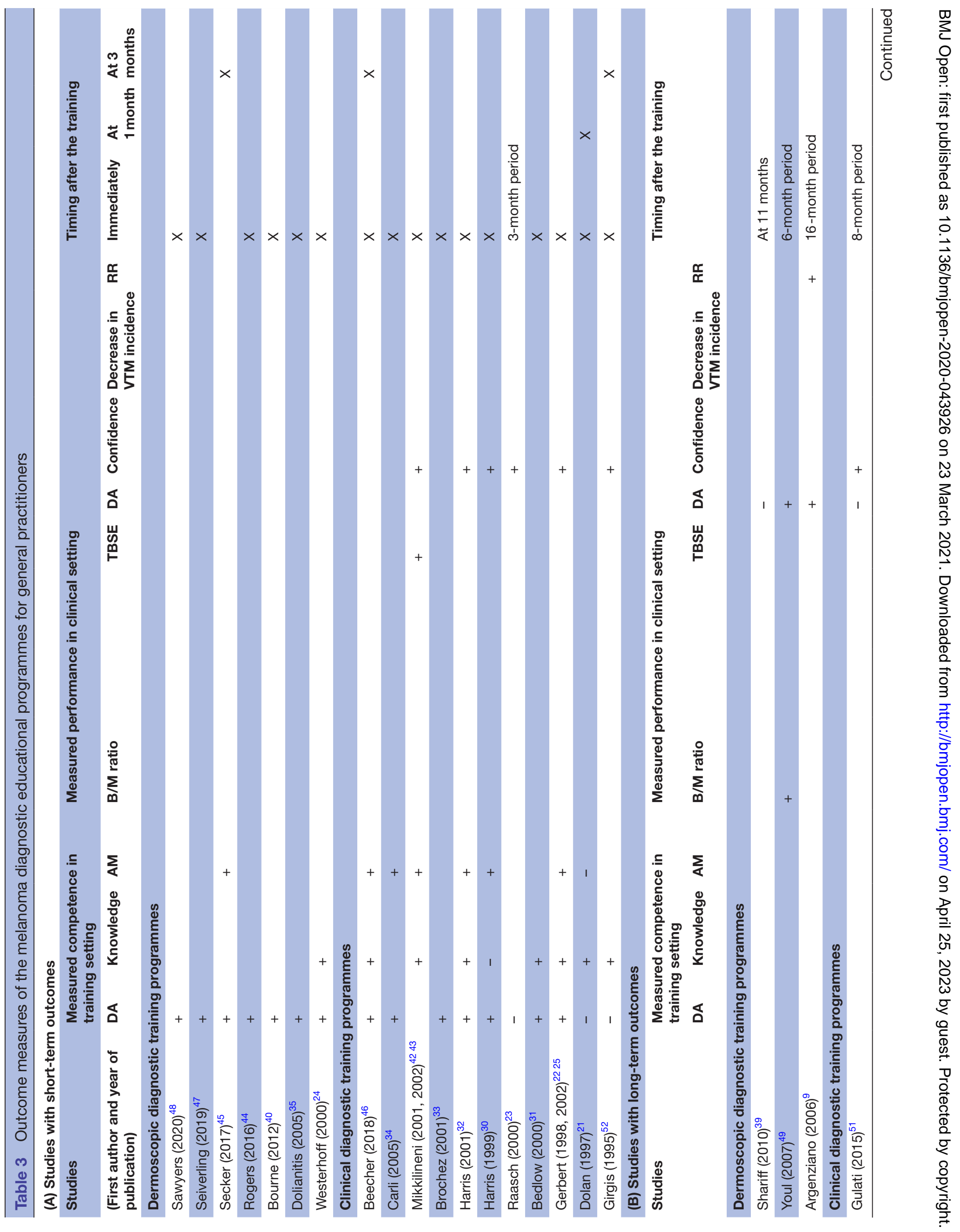




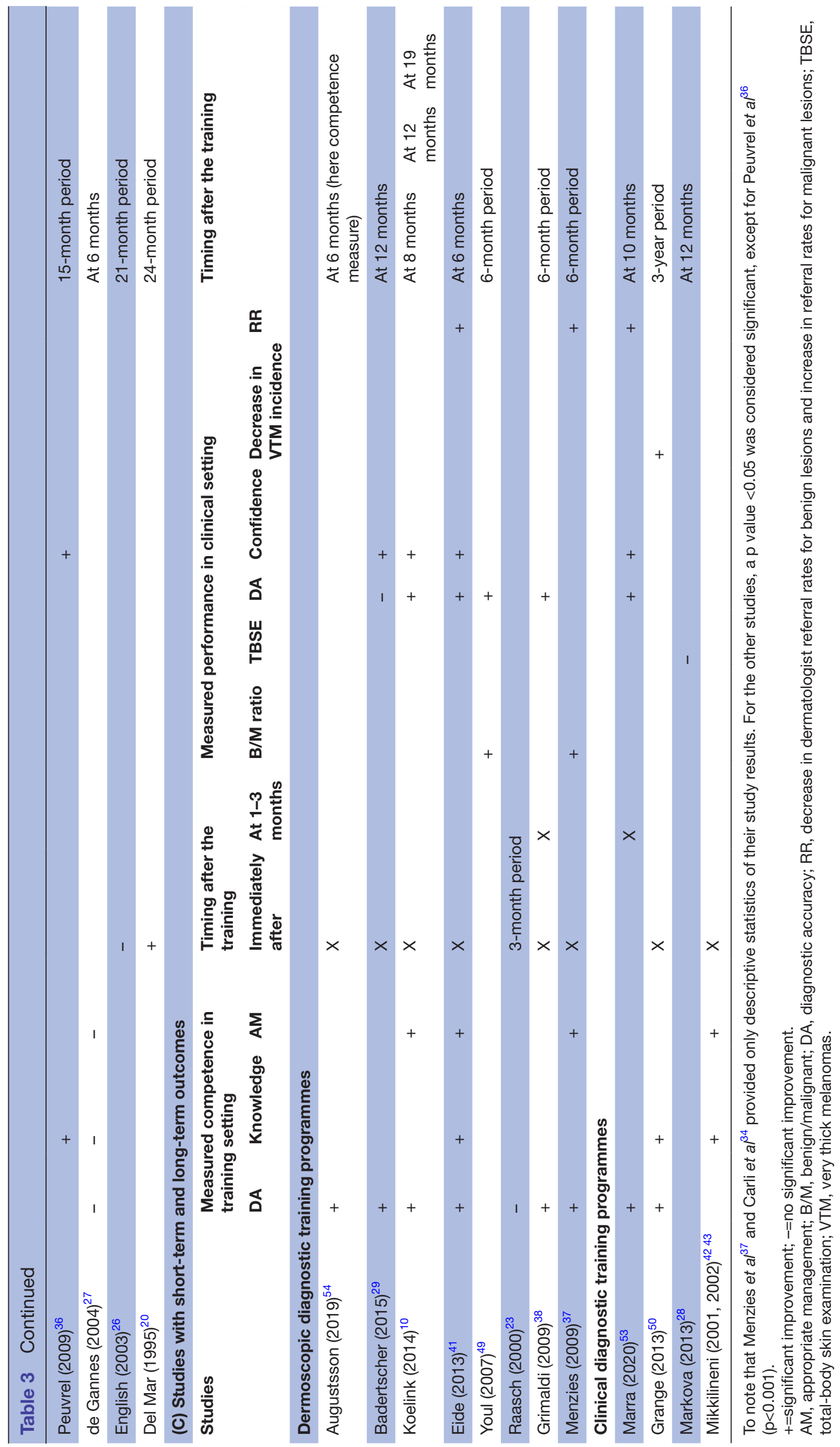

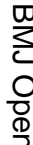

$\stackrel{\vec{F}}{\mathrm{~F}}$

흘

$\stackrel{\square}{\Omega}$

๗

$\vec{\circ}$

ట

홍.

D

กิ

움

N

N

3

วิ

N

망

흥

잉 
confidence level and number of total-body skin examinations performed before and after training, which did not reflect GPs' diagnostic ability in clinical practice. On the one hand, measuring the confidence of GPs in their own ability to diagnose melanoma is more useful in assessing the quality of a training programme than evaluating skills acquired by participants. From a pedagogical point of view, participants feel more confident when they know how to use the teaching content in daily practice, but this does not define their true diagnostic competence. ${ }^{18}$ On the other hand, the number of total-body skin examinations performed may be useful in measuring GPs' awareness of skin tumours, but not for evaluation of GPs' diagnostic skills.

\section{Long-term improvement of the GPs' performances in clinical settings}

The GPs' long-term performances measured in clinical settings were assessed for 15 educational programmes: 6 in clinical diagnosis and 9 in dermoscopic diagnosis. Ten showed a positive impact on the GPs' performances measured over periods ranging from 6 to 19 months. The most frequent observations were a decrease in referral rates to dermatologists for benign skin lesions and an improvement in the benign/malignant ratio of excised skin lesions. The internet curriculum for melanoma early detection (INFORMED) group ${ }^{41}$ reported an increase in melanoma diagnosis during a screening campaign by GPs trained with their programme in $2016 .{ }^{68}$ Furthermore, a decrease in the incidence of advanced melanomas was shown in a French department over a 3-year period after their training programme in clinical melanoma diagnosis. ${ }^{50}$ Unfortunately, two educational programs ${ }^{28} 29$ failed to maintain the GPs' acquired performances at 1year after the end of the training. The reasons might be that Markova et $a t^{28}$ chose to assess the number of total-body skin examinations performed but did not evaluate the GPs' diagnostic accuracy and that Badertscher $e t a l^{29}$ trained their GPs to use Lumio, a polarised magnifying glass with $2 \times$ magnification instead of a standard dermoscopy device (10× magnification).

To retain acquired diagnostic skills over the long term, results of a recent RCT suggested the need for 'refresher sessions at regular intervals' ${ }^{69}{ }^{70}$ In our review, nine $(60 \%)$ educational programmes evaluated in the long term provided refresher training material. Seven of these programmes were successful. In 2014, Grange et a $\tilde{l}^{0}$ produced a CD-ROM containing their teaching material and sent regular information about melanoma to the GPs. The INFORMED group ${ }^{41}$ provided GPs with a free unlimited access to their web-based course. Menzies $e t a p^{77}$ gave participating GPs an educational textbook and an unlimited e-learning access. Grimaldi $e t a l^{38}$ and Youl $e t a l^{49}$ also ensured self-assessment refresher training sessions. Marra et $a \tilde{l}^{\tilde{3}}$ found a 10-month sustainability of the diagnostic accuracy of their trained GPs and assumed that daily use of the obtained knowledge during the study period achieved this effect. Only Koelink et $a l^{10}$ who evaluated the longest post-training period (19 months) and who demonstrated sustainability of diagnostic skills did not specify whether update training modalities were provided.

However, the ideal frequency and form of updates have never been studied. An RCT, taking place in the English National Defibrillator Programme, determined that update session intervals after a medical education session should not exceed 7 months to limit the loss of acquired skills and maintain the participants' confidence. ${ }^{71}$ In the UK, a survey among GPs with special interest in dermatology stated that self-assessment learning was the most popular for refresher sessions. ${ }^{67}$ Nevertheless, they also showed that $36 \%$ of GPs who use dermoscopy in their clinical practice reported to have never updated their training skills. We found that the most appreciated form of self-assessment updates was the unlimited access to an e-learning course. In the future, this enthusiasm for online training could lead to the development of smartphone applications to train GPs in melanoma diagnosis. Some newly developed applications have currently been evaluated among medical students ${ }^{72}$ and dermatology residents. ${ }^{73}$ Initial results already looked very promising.

Finally, the variability of refresher training material provided in the educational programmes and the heterogeneity of outcome measures did not allow more robust conclusions to be drawn on the most beneficial training modality for sustainable improvements in GPs' diagnostic skills.

\section{LIMITATIONS}

This scoping review has some limitations and led inevitably to certain publication biases. We used keywords for the selection of articles, and only peer-reviewed articles were included. By limiting our research to Englishlanguage articles, some studies may also have been missed. It is also very likely that melanoma diagnostic training programmes exist in unpublished forms, for example, in university continuing medical education programmes. Moreover, we focused only on studies assessing melanoma diagnostic training methods among GPs. Therefore, we may have failed to mention some educational programmes for primary care in this review. Furthermore, educational programmes which were not evaluated in studies were overlooked. Finally, this review covers educational programmes over a 25-year period. As technology has evolved considerably over this time, some teaching methods and refresher training materials have been overshadowed by interactive online tutorials (e-learning) - all the more so with the health crisis caused by COVID-19 during which distance learning methods have developed very rapidly.

\section{CONCLUSION}

In conclusion, educational programmes trained GPs in melanoma diagnosis using clinical examination alone or dermoscopy \pm clinical diagnosis. Most reported programmes that improved the long-term diagnostic accuracy and changed routine performances of the 
GPs (ie, decrease in dermatologist referral of benign skin lesions and improvement in the benign/malignant ratio of excised skin lesions) trained their participating GPs in both diagnostic methods. The preferred teaching methods were live and e-learning, but the teaching method did not seem to influence the GPs' acquired performances. It is important to note that the educational programmes that achieved long-term sustainability of GPs' performances in daily clinical practice provided refresher training material. However, no conclusions on the most beneficial training modality to sustainably improve GPs' diagnostic skills could be drawn given the heterogeneity of outcome measures and study designs. Therefore, the optimal form and ideal frequency of these updates have yet to be defined.

Acknowledgements The authors would like to thank Graziella Messina, Research Assistant at the Health Sciences Library of the Catholic University of Louvain, UCLouvain in Brussels, for her help in developing the research strategy for this review.

Contributors EH developed the research protocol, completed the literature search and screened the articles for inclusion, extracted the data, synthesised the findings, interpreted the results and drafted the manuscript. MB screened the articles for inclusion, extracted data and critically revised the manuscript. IT developed the protocol, independently reviewed the articles for inclusion, extracted data, interpreted the results and critically revised the manuscript. All authors approved the final version.

Funding The authors have not declared a specific grant for this research from any funding agency in the public, commercial or not-for-profit sectors.

Competing interests None declared.

Patient consent for publication Not required.

Provenance and peer review Not commissioned; externally peer reviewed.

Data availability statement All data relevant to the study are included in the article or uploaded as supplementary information.

Supplemental material This content has been supplied by the author(s). It has not been vetted by BMJ Publishing Group Limited (BMJ) and may not have been peer-reviewed. Any opinions or recommendations discussed are solely those of the author(s) and are not endorsed by BMJ. BMJ disclaims all liability and responsibility arising from any reliance placed on the content. Where the content includes any translated material, BMJ does not warrant the accuracy and reliability of the translations (including but not limited to local regulations, clinical guidelines, terminology, drug names and drug dosages), and is not responsible for any error and/or omissions arising from translation and adaptation or otherwise.

Open access This is an open access article distributed in accordance with the Creative Commons Attribution Non Commercial (CC BY-NC 4.0) license, which permits others to distribute, remix, adapt, build upon this work non-commercially, and license their derivative works on different terms, provided the original work is properly cited, appropriate credit is given, any changes made indicated, and the use is non-commercial. See: http://creativecommons.org/licenses/by-nc/4.0/.

\section{ORCID iDs}

Evelyne Harkemanne http://orcid.org/0000-0001-9936-9868

Marie Baeck http://orcid.org/0000-0003-0499-7939

\section{REFERENCES}

1 Petrie T, Samatham R, Witkowski AM. Melanoma early detection: big data, bigger picture. J Invest Dermatol 2019;139:25-30.

2 van Rijsingen MCJ, van Bon B, van der Wilt GJ, et al. The current and future role of general practitioners in skin cancer care: an assessment of 268 general practitioners. Br J Dermatol 2014;170:1366-8.

3 Buckley D, McMonagle C. Melanoma in primary care. The role of the general practitioner. Ir J Med Sci 2014;183:363-8.

4 Grange F, Barbe C, Mas L, et al. The role of general practitioners in diagnosis of cutaneous melanoma: a population-based study in France. Br J Dermatol 2012;167:1351-9.
5 Goulart JM, Quigley EA, Dusza S, et al. Skin cancer education for primary care physicians: a systematic review of published evaluated interventions. J Gen Intern Med 2011;26:1027-35.

6 Bakos RM, Blumetti TP, Roldán-Marín R, et al. Noninvasive imaging tools in the diagnosis and treatment of skin cancers. Am J Clin Dermatol 2018;19:3-14.

7 Piccolo D, Ferrari A, Peris K, et al. Dermoscopic diagnosis by a trained clinician vs. a clinician with minimal dermoscopy training vs. computer-aided diagnosis of 341 pigmented skin lesions: a comparative study. Br J Dermatol 2002;147:481-6.

8 Dinnes J, Deeks JJ, Chuchu N, et al. Dermoscopy, with and without visual inspection, for diagnosing melanoma in adults. Cochrane Database Syst Rev 2018;96.

9 Argenziano G, Puig S, Zalaudek I, et al. Dermoscopy improves accuracy of primary care physicians to triage lesions suggestive of skin cancer. J Clin Oncol 2006;24:1877-82.

10 Koelink CJL, Vermeulen KM, Kollen BJ, et al. Diagnostic accuracy and cost-effectiveness of dermoscopy in primary care: a cluster randomized clinical trial. J Eur Acad Dermatol Venereol 2014;28:1442-9.

11 Jones OT, Jurascheck LC, van Melle MA, et al. Dermoscopy for melanoma detection and triage in primary care: a systematic review. BMJ Open 2019;9:e027529.

12 Herschorn A. Dermoscopy for melanoma detection in family practice. Can Fam Physician 2012;58:740-5.

13 Chia A, Trevena L. A systematic review of training to improve melanoma diagnostic skills in general practitioners. $J$ Cancer Educ 2016;31:730-5.

14 Fee JA, McGrady FP, Rosendahl C. Training primary care physicians in dermoscopy for skin cancer detection: a scoping review. J. Cancer Educ 2019.

15 Arksey H, O'Malley L. Scoping studies: towards a methodological framework. Int J Soc Res Methodol Theory Pract 2005.

16 Levac D, Colquhoun H, O'Brien KK. Scoping studies: advancing the methodology. Implement Sci 2010;5:69.

17 Tricco AC, Lillie E, Zarin W, et al. PRISMA extension for scoping reviews (PRISMA-ScR): checklist and explanation. Ann Intern Med 2018;169:467-73.

18 Moore DE. How physicians learn and how to design learning experiences for them: an approach based on an interpretive review of evidence. In: Continuing education in the health professions: improving healthcare through lifelong learning, 2008.

19 Moher D, Liberati A, Tetzlaff JAD. PRISMA 2009 flow diagram. Prism 2009.

20 Del Mar CB, Green AC. Aid to diagnosis of melanoma in primary medical care. BMJ1995;310:492-5.

21 Dolan NC, Ng JS, Martin GJ, et al. Effectiveness of a skin cancer control educational intervention for internal medicine housestaff and attending physicians. J Gen Intern Med 1997;12:531-6.

22 Gerbert B, Bronstone A, Wolff M, et al. Improving primary care residents' proficiency in the diagnosis of skin cancer. $J$ Gen Intern Med 1998;13:91-7.

23 Raasch BA, Hays R, Buettner PG. An educational intervention to improve diagnosis and management of suspicious skin lesions. $J$ Contin Educ Health Prof 2000;20:39-51.

24 Westerhoff K, McCarthy WH, Menzies SW. Increase in the sensitivity for melanoma diagnosis by primary care physicians using skin surface microscopy. Br J Dermatol 2000;143:1016-20.

25 Gerbert B, Bronstone A, Maurer T. The effectiveness of an Internetbased tutorial in improving primary care physicians' skin cancer triage skills. J Cancer Educ 2002.

26 English DR, Burton RC, del Mar CB, et al. Evaluation of aid to diagnosis of pigmented skin lesions in general practice: controlled trial randomised by practice. BMJ 2003;327:375.

27 de Gannes GC, Ip JL, Martinka M, et al. Early detection of skin cancer by family physicians: a pilot project. J Cutan Med Surg 2004;8:103-9.

28 Markova A, Weinstock MA, Risica P, et al. Effect of a web-based curriculum on primary care practice: basic skin cancer triage trial. Fam Med 2013;45:558-68.

29 Badertscher N, Tandjung R, Senn O. A multifaceted intervention: no increase in general practitioners' competence to diagnose skin cancer (minSKIN) - randomized controlled trial. J Eur Acad Dermatology Venerol 2015.

30 Harris JM, Salasche SJ, Harris RB. Using the Internet to teach melanoma management guidelines to primary care physicians. J Eval Clin Pract 1999;5:199-211.

31 Bedlow AJ, Cliff S, Melia J, et al. Impact of skin cancer education on general practitioners' diagnostic skills. Clin Exp Dermatol 2000;25:115-8. 
32 Harris JM, Salasche SJ, Harris RB. Can Internet-based continuing medical education improve physicians' skin cancer knowledge and skills? J Gen Intern Med 2001;16:50-6.

33 Brochez L, Verhaeghe E, Bleyen L, et al. Diagnostic ability of general practitioners and dermatologists in discriminating pigmented skin lesions. J Am Acad Dermatol 2001;44:979-86.

34 Carli P, De Giorgi V, Crocetti E, et al. Diagnostic and referral accuracy of family doctors in melanoma screening: effect of a short formal training. Eur J Cancer Prev 2005;14:51-5.

35 Dolianitis C, Kelly J, Wolfe R, et al. Comparative performance of 4 dermoscopic algorithms by nonexperts for the diagnosis of melanocytic lesions. Arch Dermatol 2005;141:1008-14.

36 Peuvrel L, Quereux G, Jumbou O, et al. Impact of a campaign to train general practitioners in screening for melanoma. Eur $J$ Cancer Prev 2009;18:225-9.

37 Menzies SW, Emery J, Staples M, et al. Impact of dermoscopy and short-term sequential digital dermoscopy imaging for the management of pigmented lesions in primary care: a sequentia intervention trial. Br J Dermatol 2009;161:1270-7.

38 Grimaldi L, Silvestri A, Brandi C, et al. Digital epiluminescence dermoscopy for pigmented cutaneous lesions, primary care physicians, and telediagnosis: a useful tool? J Plast Reconstr Aesthet Surg 2009;62:1054-8

39 Shariff Z, Roshan A, Williams AM, et al. 2-Week wait referrals in suspected skin cancer: does an instructional module for general practitioners improve diagnostic accuracy? Surgeon 2010;8:247-51.

40 Bourne P, Rosendahl C, Keir J, et al. BLINCK-A diagnostic algorithm for skin cancer diagnosis combining clinical features with dermatoscopy findings. Dermatol Pract Concept 2012;2:202a12.

41 Eide MJ, Asgari MM, Fletcher SW, et al. Effects on skills and practice from a web-based skin cancer course for primary care providers. $J$ Am Board Fam Med 2013;26:648-57.

42 Mikkilineni R, Weinstock MA, Goldstein MG, et al. The impact of the basic skin cancer triage curriculum on provider's skin cancer control practices. J Gen Intern Med 2001;16:302-7.

43 Mikkilineni R, Weinstock MA, Goldstein MG. The impact of the basic skin cancer triage curriculum on providers' skills, confidence, and knowledge in skin cancer control. Prev Med 2002.

44 Rogers T, Marino ML, Dusza SW, et al. A clinical aid for detecting skin cancer: the triage amalgamated dermoscopic algorithm (TadA). J Am Board Fam Med 2016;29:694-701.

45 Secker LJ, Buis PAJ, Bergman W, et al. Effect of a dermoscopy training course on the accuracy of primary care physicians in diagnosing pigmented lesions. Acta Derm Venereol 2017;97:263-5.

46 Beecher SM, Keogh C, Healy C. Dedicated general practitioner education sessions can improve diagnostic capabilities and may have a positive effect on referral patterns for common skin lesions. Ir J Med Sci 2018;187:959-63.

47 Seiverling EV, Ahrns HT, Greene A, et al. Teaching benign skin lesions as a strategy to improve the triage amalgamated dermoscopic algorithm (TadA). J Am Board Fam Med 2019;32:96-102.

48 Sawyers EA, Wigle DT, Marghoob AA, et al. Dermoscopy training effect on diagnostic accuracy of skin lesions in Canadian family medicine physicians using the triage Amalgamated Dermoscopic algorithm. Dermatol Pract Concept 2020;10:e2020035.

49 Youl PH, Raasch BA, Janda M, et al. The effect of an educational programme to improve the skills of general practitioners in diagnosing melanocytic/pigmented lesions. Clin Exp Dermatol 2007;32:365-70.

50 Grange F, Woronoff AS, Bera R, et al. Efficacy of a general practitioner training campaign for early detection of melanoma in France. Br J Dermatol 2014;170:123-9.

51 Gulati A, Harwood CA, Rolph J, et al. Is an online skin cancer toolkit an effective way to educate primary care physicians about skin cancer diagnosis and referral? J Eur Acad Dermatol Venereol 2015;29:2152-9.

52 Girgis A, Sanson-Fisher RW, Howe C, et al. A skin cancer training programme: evaluation of a postgraduate training for family doctors. Med Educ 1995;29:364-71.
53 Marra E, van Rijsingen MCJ, Alkemade JAC, et al. The effect of a dermato-oncological training programme on the diagnostic skills and quality of referrals for suspicious skin lesions by general practitioners. Br J Dermatol 2021:184:538-44.

54 Augustsson A, Paoli J. Effects of a 1-day training course in dermoscopy among general practitioners. Dermatol Pract Concept 2019;9:195-9.

55 Shaikh WR, Geller A, Alexander G, et al. Developing an interactive web-based learning program on skin cancer: the learning experiences of clinical educators. J Cancer Educ 2012;27:709-16.

56 Badertscher N, Rosemann T, Tandjung R, et al. minSKIN does a multifaceted intervention improve the competence in the diagnosis of skin cancer by general practitioners? Study protocol for a randomised controlled trial. Trials 2011:12:165.

57 Weinstock MA, Goldstein MG, Dubé CE, et al. Basic skin cancer triage for teaching melanoma detection. J Am Acad Dermatol 1996;34:1063-6.

58 Friedman RJ, Rigel DS, Kopf AW. Early detection of malignant melanoma: the role of physician examination and self-examination of the skin. CA Cancer J Clin 1985;35:130-51.

59 Menzies SW. A method for the diagnosis of primary cutaneous melanoma using surface microscopy. Dermatol Clin 2001;19:299-305.

60 Stolz W, Riemann A, Cognetta AB. Abcd rule of dermatoscopy: a new practical method for early recognition of malignant melanoma. Eur J Dermatology 1994

61 Argenziano G, Fabbrocini G, Carli P, et al. Epiluminescence microscopy for the diagnosis of doubtful melanocytic skin lesions. Arch Dermatol 1998;134.

62 Pagnanelli G, Soyer HP, Argenziano G, et al. Diagnosis of pigmented skin lesions by dermoscopy: web-based training improves diagnostic performance of non-experts. $\mathrm{Br} \mathrm{J}$ Dermatol 2003:148:698-702.

63 Soyer HP, Argenziano G, Zalaudek I, et al. Three-point checklist of dermoscopy. A new screening method for early detection of melanoma. Dermatology 2004;208:27-31.

64 Chappuis P, Duru G, Marchal O, et al. Dermoscopy, a useful tool for general practitioners in melanoma screening: a nationwide survey. $\mathrm{Br}$ J Dermatol 2016;175:744-50.

65 Oliveria SA, Heneghan MK, Cushman LF, et al. Skin cancer screening by dermatologists, family practitioners, and internists: barriers and facilitating factors. Arch Dermatol 2011;147:39-44.

66 Kittler $\mathrm{H}$, Pehamberger $\mathrm{H}$, Wolff $\mathrm{K}$, et al. Diagnostic accuracy of dermoscopy. Lancet Oncol 2002;3:159-65.

67 Jones OT, Jurascheck LC, Utukuri M, et al. Dermoscopy use in UK primary care: a survey of GPs with a special interest in dermatology. J Eur Acad Dermatol Venereol 2019;33:1706-12.

68 Weinstock MA, Ferris LK, Saul MI, et al. Downstream consequences of melanoma screening in a community practice setting: first results. Cancer 2016;122:3152-6.

69 Robinson JK, Jain N, Marghoob AA, et al. A randomized trial on the efficacy of mastery learning for primary care provider melanoma opportunistic screening skills and practice. J Gen Intern Med 2018;33:855-62.

70 Robinson JK, MacLean M, Reavy R. Dermoscopy of concerning pigmented lesions and primary care providers' referrals at intervals after randomized trial of mastery learning. J Gen Intern Med 2018.

71 Woollard M, Whitfield R, Newcombe RG, et al. Optimal refresher training intervals for AED and CPR skills: a randomised controlled trial. Resuscitation 2006;71:237-47.

72 Lacy FA, Coman GC, Holliday AC, et al. Assessment of smartphone application for teaching intuitive visual diagnosis of melanoma. JAMA Dermatol 2018:154:730-1.

73 Nelson KC, Gershenwald JE, Savory SA, et al. Telementoring and smartphone-based answering systems to optimize dermatology resident dermoscopy education. J Am Acad Dermatol 2019;81:e27-8. 